\title{
Economic evaluation of Nearly Zero Energy Cities
}

\author{
Manuel Villa-Arrieta ${ }^{a, *}$, Andreas Sumper ${ }^{b}$ \\ ${ }^{a}$ Escola Tècnica Superior d'Enginyeria Industrial de Barcelona (ETSEIB), Universitat Politècnica de Catalunya \\ (UPC), Av. Diagonal, 647. 08028 Barcelona, Spain \\ ${ }^{b}$ Centre d'Innovació Tecnològica en Convertidors Estàtics i Accionaments (CITCEA-UPC), Universitat Politècnica \\ de Catalunya (UPC), Av. Diagonal, 647, Pl. 2. 08028 Barcelona, Spain
}

\section{Graphical abstract}

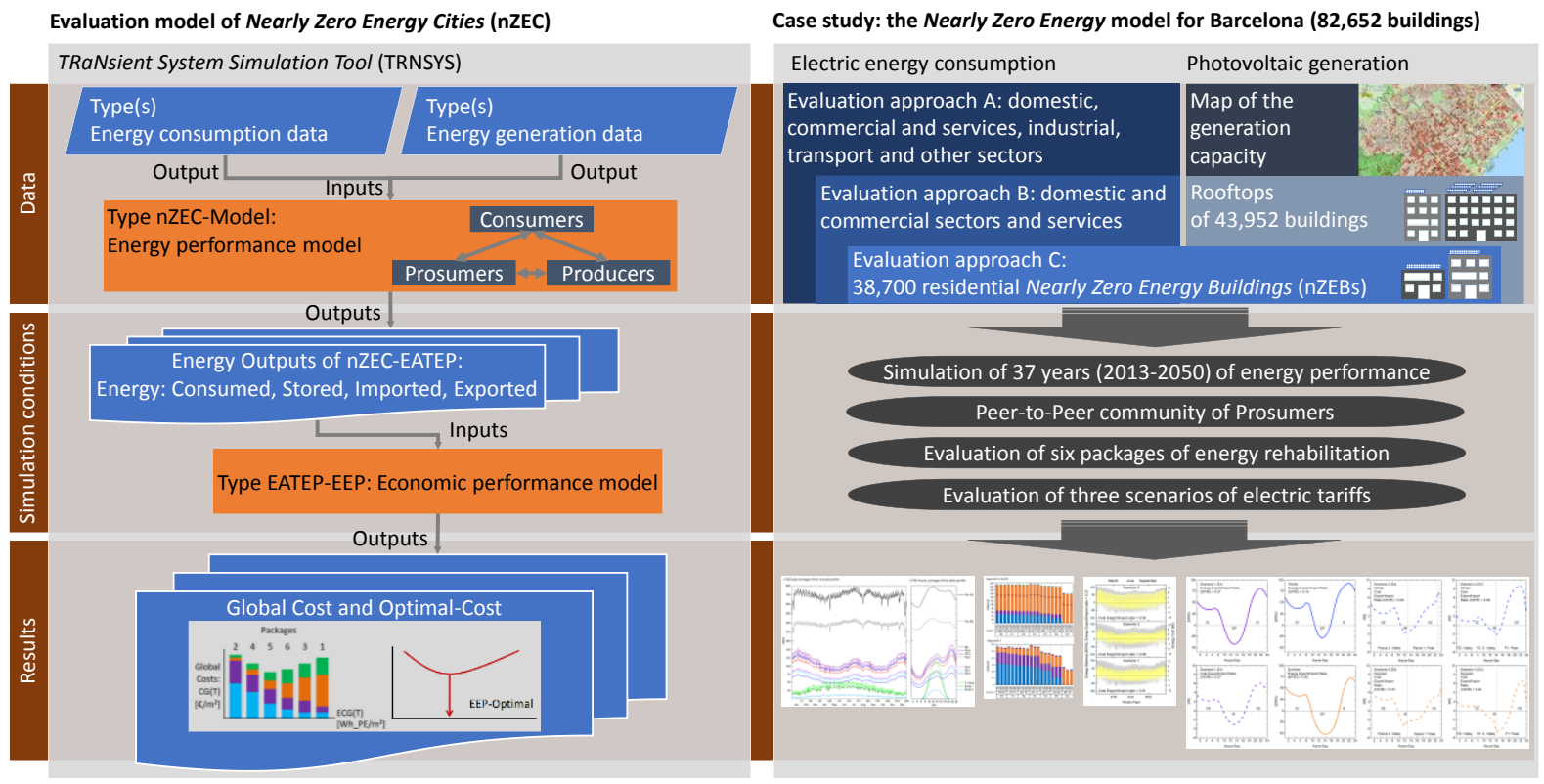

\section{Abstract}

As a contribution to the study of the urban energy transition, this paper proposes a novel model of energy-economic evaluation of the cities self-sufficiency and presents its application in the form of a case study. The objective of this study was to analyse the scope of the investment in the photovoltaic self-consumption of buildings in order to promote the creation of Prosumers communities within the cities. The operation of this model is based on the scalability of the Nearly Zero Energy concept from buildings to cities and seeks to evaluate Nearly Zero Energy Cities (nZEC): cities made up of Nearly Zero Energy Buildings (nZEB) and other installations of distributed generation to cover their energy demand by use of local renewable resources to the detriment of external resources. By using public data, we apply this model with the aim of economically evaluating the investment of six packages of energy rehabilitation and photovoltaic selfconsumption in $17 \%$ of the residential buildings $(37,800)$ in the city of Barcelona. To do this, we simulated 37 years of electricity distribution among Consumers, Producers and a hypothetical peer-

\footnotetext{
${ }^{*}$ Corresponding author. E-mail address: manuel.ricardo.villa@upc.edu
} 
to-peer community of Prosumers during the period 2014-2050 in hourly time intervals. The results indicated that the photovoltaic self-consumption and the local markets of Prosumers help to reduce primary energy consumption, the energy costs, and the $\mathrm{CO}_{2}$ emissions.

Keywords: Nearly Zero Energy Buildings (nZEB), Nearly Zero Energy Cities (nZEC), Urban energy transition, Photovoltaic self-consumption, Prosumer

\begin{tabular}{|c|c|c|c|}
\hline \multicolumn{4}{|l|}{ Nomenclature } \\
\hline Csr & Consumers & NZEB & Net Zero Energy Building \\
\hline CEG(T) & Global Energy Cost & nZEC & Nearly Zero Energy City \\
\hline CG(T) & Global Cost & $\mathrm{P}$ & Electric tariff period (P1, $\mathrm{P} 2, \mathrm{P} 3)$ \\
\hline $\mathrm{CIG}(\mathrm{T})$ & Global Investment Cost & $\mathrm{Pg}$ & Package: Set of EEM \\
\hline CRG(T) & Global Running Cost & PCharge_ $\gamma(\mathrm{h})$ & Power charges \\
\hline CsrS & Consumers with electric energy storage & Pdr & Producer (IPP, or utility generator) \\
\hline EA & Electric energy endogenous available & PEU_Y (h) & Energy price \\
\hline ECharge_ $\gamma(\mathrm{h})$ & Electric energy charges & Psr & Prosumer \\
\hline ED & Electric energy demand & PsrS & Prosumers with electric energy storage \\
\hline EEM & Energy Efficiency Measures & $\operatorname{Rd}(\mathrm{t})$ & Discount Rate, \\
\hline EG & Electric energy generation & $\mathrm{RI}$ & Inflation Rate \\
\hline EI & Electric energy imported & RR & Real Interest Rate \\
\hline Endo & Endogenous electric energy consumed (Local) & $\mathrm{t}$ & Each of the years of $T$ \\
\hline EP & Electric energy exported & $T$ & Economic evaluation period (Years of 8760 hours) \\
\hline EPBD & Energy Performance of Buildings Directive & Tn & Lifespan \\
\hline ES & Electric energy storage & Type & Subroutine of TRNSYS \\
\hline EValue_Y(h) & Economic value of the energy flow & UTC & Urban Energy Transition \\
\hline Exo & Exogenous electric energy (external of the nZEC) & $V F \_j(T)$ & Final value of the Component \\
\hline NZEB & Net Zero Energy Building & & \\
\hline
\end{tabular}

\section{Introduction}

Cities are home to more than half of the world population and this has an impact in that $70 \%$ of the world energy consumption and greenhouse gas emissions are concentrated in these urban areas [1]. Urbanization has led to an increase in the proportion of urban energy use of the total global primary energy supply [2]. In view of the fact that the projections up until 2050 indicate that the world population will be $30 \%$ larger [3], and that $68 \%$ of it will be urban [4], cities play a fundamental role in the process of energy transition [5]. This process requires a structural change in the world energy sector, moving towards the increase of energy efficiency and the consumption of renewable energy resources, and the reduction of the consumption of fossil energy resources $[6,7]$. In this sense, the solar resource plays a notable role, given the uniformity of its distribution on a global scale [8]. Although each economic region of the world has different drivers in this transition [6,9], there is a general consensus to focus on working towards a higher level of effectiveness when it comes to 
energy consumption in various areas such as industry, transport and building (housing, commercial and services) [10]; In this sense, within the framework of the Paris agreement, the European Union (EU) recognizes the importance of the role of cities in moving towards a low carbon economy [11].

A high percentage of the energy demand of cities is concentrated in their buildings [10] and in order to promote the increase of energy efficiency, herein exists the greatest potential for savings [2]. Effective energy transition from the cities implies Urban Energy Transition (UET), therefore, deepening the efforts in promoting Distributed Generation (DG) and reorientating the consumption and energy supply of buildings and communities (buildings group). Thus, it is necessary to concentrate economic resources in the investment of Energy Efficiency Measures (EEM) and selfconsumption systems [12,13]; as well as facilitating the creation of the Prosumer figure [14]: Consumers who, due to their self-consumption capacity can, by virtue of the regulatory conditions of the electrical systems and market, export energy to the distribution grid [15]. From the integration of renewable energies in buildings and communities, the zero energy concept is understood as the frontier of energy efficiency, energy self-sufficiency and urban sustainability $[16,17]$. This concept can be defined in general terms as the reduction of primary energy consumption and the generation of energy in situ from renewable resources in facilities or focuses of consumption by means of investment in EEM and self-consumption technologies. When the amount of energy required is less than the quantity generated in situ, and regardless of any energy storage that may exist, these focuses of energy consumption can export their energy surpluses to the grid.

In this sense in [18-20] the Net and Nearly Zero Energy concepts are analysed as a sequence of steps towards buildings' self-consumption. Adapting this analysis to the definition of UET, Nearly Zero Energy can be an initial step for a net balance or Net Zero Energy, and this can also be a previous step towards the total exportation of energy surpluses or Net Plus Energy of cities. In this context, in order to contribute to the study of the reduction of negative environmental externalities that causes the high consumption of fossil energy resources in cities, this paper aims to propose an energyeconomic evaluation model to study the energy self-sufficiency of cities. With this, we seek to verify the hypothesis that the use of local solar resources, through the photovoltaic self-sufficiency of the buildings, and the distribution of electrical energy among Prosumers, Consumers and Producers, helping to reduce the consumption of primary energy together with lowering energy costs and $\mathrm{CO}_{2}$ emissions.

The proposed evaluation model, called nZEC-EATEP, is novel and replicable in any city due to being based on the scalability of the concept Nearly Zero Energy from a building (Nearly Zero Energy Buildings, nZEB) to city level (Nearly Zero Energy City, nZEC). Regarding to the evaluation of nZEC, $[21,22]$ analyse the generation capacity of urban buildings to maintain the balance between that and 
their energy consumption. Faced with these proposals, nZEC-EATEP works within the TRaNsient System Simulation Tool (TRNSYS) and is the union of two independent models that can be fed with other models or software. The first of these independent models is an energy performance simulation model of nZECs, called nZEC-Model. The second one is the economic evaluation model of the energy systems Economic Assessment Tool of Energy Projects (EATEP) proposed in [23]. The operation of nZEC-EATEP consists of the evaluation of the costs in reducing the energy consumption and the use of local renewable resources (endogenous energy) and thus reducing the use of external resources (exogenous energy). Through this design the model allows: i) to simulate the energy performance of the distribution of energy between Producers, Prosumers and Consumers; ii) evaluate different packages of EEM at a city level and self-consumption to calculate, at the same level, the Global Cost and Optimal-Cost indicators presented in the Energy Performance of Buildings Directive (EPBD) of the European Union [24,25]; and iii) configure the energy distribution under different market models.

Using public data obtained by local energy agencies, the nZEC-EATEP was applied to study the energy self-sufficiency of Barcelona (Spain). In this study we evaluate the costs to take advantage of the city's photovoltaic (PV) self-sufficiency capacity by analysing 82,652 of its buildings, the city's electricity consumption in three approaches, and three electricity tariff scenarios. The analysis of these buildings included: i) the capacity of energy saving and PV self-consumption of 38,700 residential buildings (46.82\%), defining them as nZEBs in six energy rehabilitation Packages; ii) the peer-to-peer distribution of electrical energy among these nZEBs, defining them as Prosumers; and iii) the PV generation capacity of the remaining 43,952 buildings (53.18\%). Specifically, the study of this nZEC model for Barcelona sought to achieve three objectives: $i$ ) to calculate the cost and primary energy savings that these packages allow; ii) to determine the package that allows the greatest reduction in primary energy consumption at the lowest cost; and iii) identify which current electricity tariff (Spain) is more favourable for the investment of these energy self-consumption measures.

The concept of economic evaluation is broad and includes the analysis of financial indicators on the return on investment. At the scale of a city, the evaluation of a Zero Energy model in this study is based on the calculation of the Global Cost and Optimal-Cost indicators without analysing the returns of the possible nZEB investments that residential Consumers could make to become Prosumers. Similarly, the scope of this study does not address the investment decisions in energy rehabilitation measures that public entities make to reduce their energy consumption. Likewise, this study does not address the scope of an established budget to reduce the energy consumption of buildings in a city. However, in this line of research, the works of $[26,27]$ do study the investments in 
energy rehabilitation of buildings using decision models. Our work focuses on the study of the total self-consumption capacity of cities.

The document is divided as follows: in the first instance, a review of the cutting-edge concept Nearly Zero Energy applied at a city level in terms of energy self-consumption is presented; subsequently, the proposed evaluation model is described; and finally, the evaluation of a nZEC-Model for Barcelona is presented, together with the results and conclusions obtained.

\section{Literature review}

As mentioned above, the Nearly Zero Energy City ${ }^{1,2}$ concept is the frontier of energy selfconsumption, and this is based on the use of renewable energy resources in buildings [28]. The literature about nZEBs on this topic is extensive [29]. The nZEBs are a link in the Smart Cities development work chain $[30,31]$, although the growth in the number of nZEBs in the urban electrical systems poses challenges and benefits in maintaining of the grid [32,33]. In Europe, the evaluation of the nZEBs has been promoted by the EPBD. On a larger scale, [34,35] propose a circular exergy model as well as studies that may carry the net-zero concept to net-zero energy and net-zero exergy cities. On that same issue, [36] reports the increase of studies of this nature under the concept of energy autonomy in sustainable communities. In [37] the concept of a Cooperative Net Zero Energy Community is introduced. In isolated systems [38,39] analyse self-consumption on islands; and in this same way, $[40,41]$ analyse the integration of renewable energies in islands through microgrid and Smart Grid technologies. And specifically regarding carbon emissions, [42,43] study the classification of cities with zero carbon emission composed of buildings with zero emissions.

At the level of evaluation of the Zero Energy city concept, [44] provides an overview of the existing assessment tools and methods, comparing their criteria and key parameters. Similarly, [45] reviews the crucial role of building performance simulation to reach building's zero energy status. [46] proposes an evaluation methodology for this purpose, based on the availability of geometry, building standards and useable data. [47] presents a development plan for the rehabilitation of groups of buildings to obtain a Zero Energy city. At these levels of evaluation, the generation in situ happens to be considered as DG in charge of Prosumers and Producers [48,49], which must cover the energy demand of other sectors such as transport, industry, commerce and services [16].

\footnotetext{
${ }^{1}$ A systematic search of the web pages of Web of Science and Scopus databases for the terms "nearly zero energy city", "net zero energy city", "nearly zero energy cities", "net zero energy cities", "zero energy city", and "zero energy cities" produced a result of 10 references.

2 In this search several references were also identified on the development of technical solutions for the promotion of "net zero energy city districts" within the framework of the European project FP7 project RE-SIZED (Research Excellence for Solutions and Implementation of Net Zero Energy City Districts).
} 
Likewise, the exchange of energy at these lower levels of the electric distribution implies the participation of these actors in local energy markets [50].

On the other hand, self-consumption is not understood without the presence of storage systems to support the intermittency of renewable energies and the lag that these energies have with respect to consumption curves. In this sense, [51,52] report benefits with the analysis of tariff systems for access to the grid. Benefits that, as indicated in $[53,54]$, depend on the parameters of the Consumer's load profile and the size of this type of systems [55]. Regarding tariff systems or markets that can encourage investment in zero energy communities, [56] reports the benefits of dynamic price rates for PV self-consumption. Also, $[57,58]$ validate the operation and benefits of peer-to-peer models in local markets. Finally, with respect to the case study in this paper, in [59] a real-time model of optimization of PV self-consumption with batteries is studied in real installations in Barcelona, which allows for an increase in the income from the export of surplus energy to the grid with a dynamic tariff.

\section{Description of the evaluation model}

The nZEC-EATEP model is the union of a simulation model of nZECs, called nZEC-Model, and the energy systems economic evaluation model EATEP. Its operation consists of the evaluation of the economic performance of the energy performance of the energy self-sufficiency process of cities. The process derived from the increase of DG and of services aggregates to the urban electrical system. Figure 1 conceptualizes the methodological basis of the nZEC-EATEP model, the UET. This model is as follows. First, $i-F 1)$ : the energy demand increases due to the increase of the urban population, and the consumption decreases in relation to the increase of the energy efficiency in the buildings and electrical grid. Then, ii-F1) as energy self-consumption becomes more present in buildings with the entry of nZEBs and NZEBs, the consumption of endogenous energy increases and decreases that of exogenous energy. Finally, iii-F1) the nZEC-EATEP allows for the stimulation of the energy self-consumption of nZECs and the calculation of the current value of the investment, operation and energy costs. 


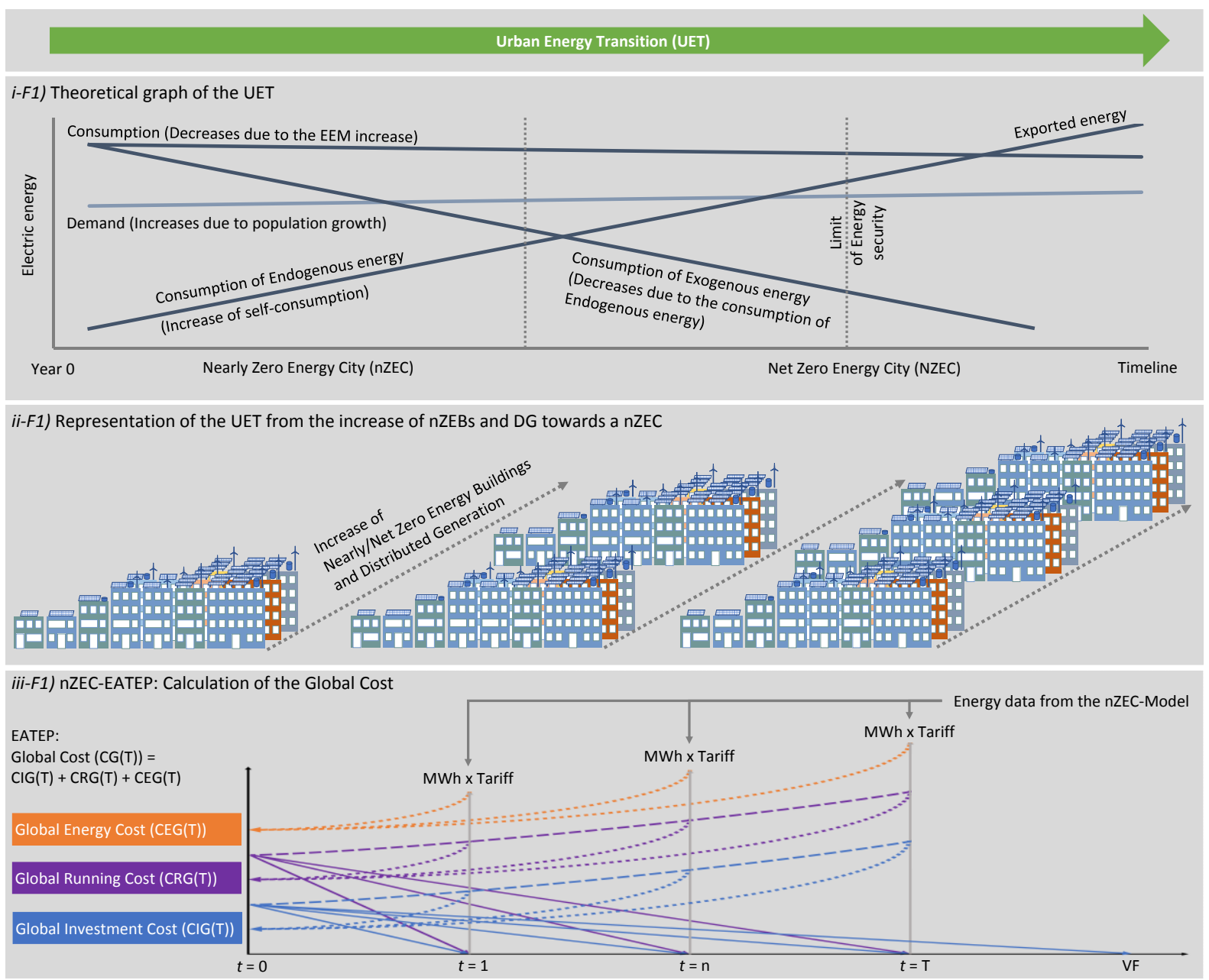

Figure 1. Graphic representation of the Urban Energy Transition (UET), as a conceptualization of the methodological basis of the nZEC-EATEP model.

The analysis of energy performance in the nZEC-Model refers to the simulation and accounting of energy flows exchanged between Consumers (Consumer installations within the city), Prosumers (nZEBs) and Producers (DG systems) to maintain the energy balance between the energy demanded by the city and the energy that is endogenous and exogenous to it in hourly time intervals. The energy demanded is the energy demanded by Consumers and Prosumers, the endogenous energy is the energy generated by Prosumers and Producers, and the exogenous energy is the energy generated by outside the urban area of the city.

On the other hand, the economic performance evaluation, carried out in the EATEP, is the accounting of the investment costs of the EEM, self-consumption and DG, and of the costs and revenues produced by the exchange of the energy flows. This tool can evaluate different packages of self-consumption and EEM in order to calculate the Global Cost at a city level (net present value of the initial investment and the costs of component replacement, maintenance and energy) and 
Optimal-Cost (graphic identification of the package that has the lowest global cost and allows for the reduction of the primary energy consumption of the city).

The nZEC-EATEP model was built in TRNSYS. Figure 2 presents the operation of the nZEC-Model. $i$-F2) indicates the operation of the model in the TRNSYS subroutines (Types) wherein are included Types of generation and energy demand of Producers, Prosumers and Consumers that deliver data (Inputs) to the nZEC-Model, whose results (Outputs) feed the EATEP, and where this Type delivers the economic and financial results for all packages of evaluated energy efficiency and self-consumption measures. ii-F2) presents the conceptual functioning of the nZEC-Model, wherein its algorithm seeks to maintain the energy balance between the endogenous energy of the nZEC and the energy exogenous to it. iii-F2) presents this algorithm in a general way. iv-F2) and $v-F 2$ ) describe, respectively, the structure of the cash flows calculated in the EATEP and the indicators of this tool. The operation of the energy simulation model and the economic evaluation model are described below.
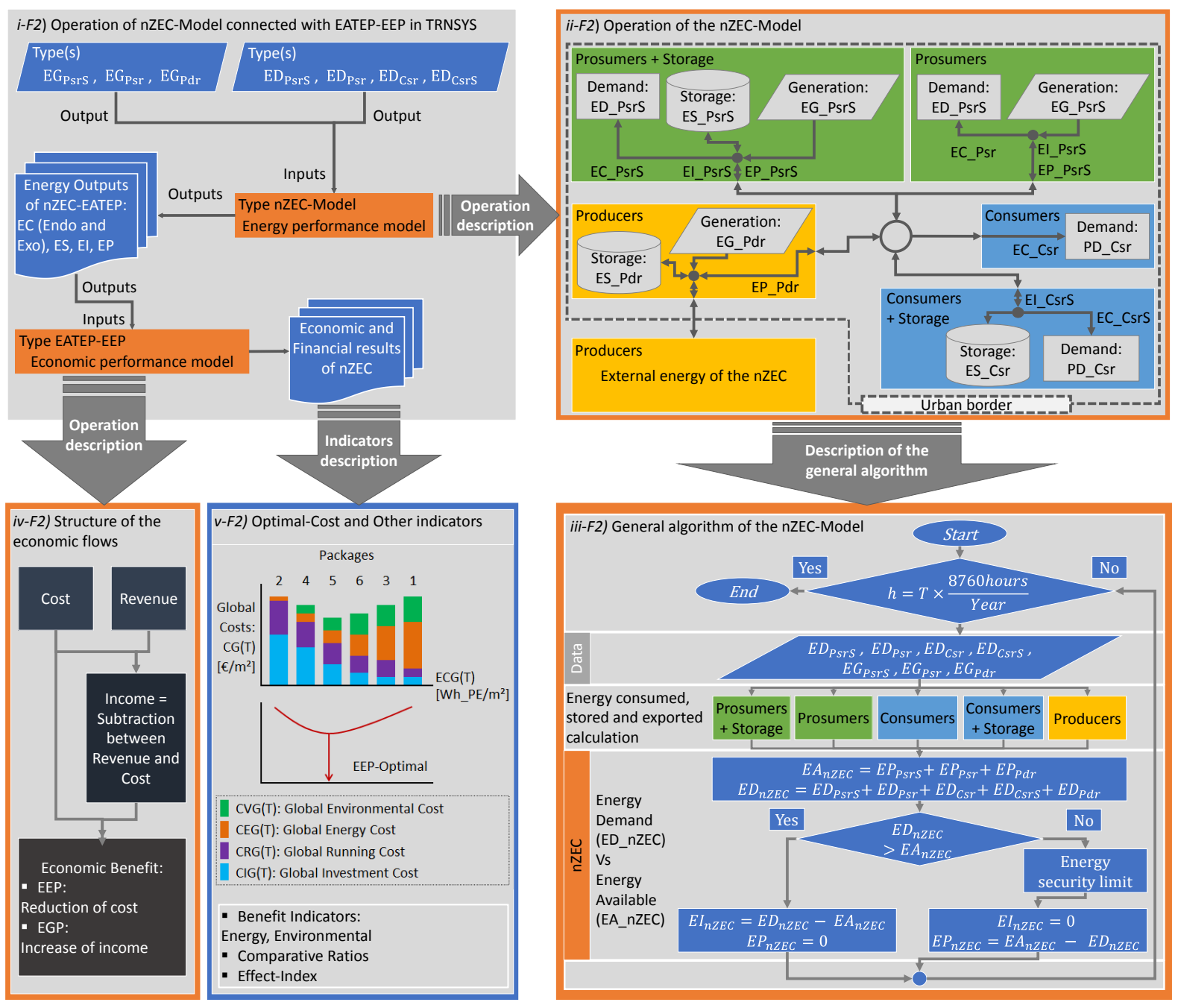

Figure 2. Graphic description of the nZEC-EATEP model. Note: $i v-F 2$ ) and $v$-F2) adapted from [23]. 


\subsection{Energy performance evaluation of Nearly Zero Energy Cities}

As mentioned above, the nZEC-Model simulates the energy balance in the nZEC in hourly intervals for any period of economic evaluation $(T)$. Based on the energy demand of Prosumers and Consumers, the availability of endogenous energy and the following energy distribution conditions, the amount of exogenous energy needed to maintain the energy balance at each time step is determined: i) The exchange of energy works in a basic state without conditions of energy markets, which can be included from another subroutine; ii) Endogenous energy is consumed as a priority to exogenous energy, first of all meeting the demand of Prosumers and then that of Consumers; iii) The self-consumption (ECG) and consumption of energy storage (ECS) are priorities, in this order, so only energy is exported when the storage systems are full (Energy Storage Accumulated, ESA); iv) The importation of exogenous energy is the responsibility of the Producers.

From these conditions, the destination of the available energy (EA) in the nZEC is consumed as imported energy (EI) in the following order of priority: Csr, CsrS, Psr, PsrS. Subsequently, Pdr imports energy from the outside of the nZEC. Details are as follows:

- Consumers (Csr): Psr (Case1); PsrS (Case2); CsrS (Case3); or Pdr (Case4).

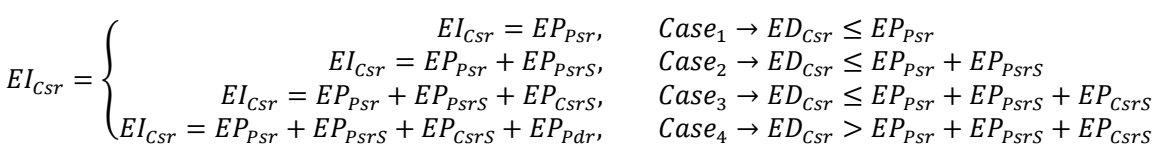

- Consumers + Storage (CsrS): Psr (Case1); or PsrS (Case2) and Pdr (Case3).

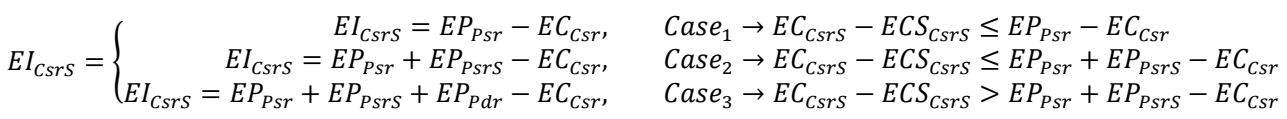

- Prosumers (Psr): PsrS (Case1); PsrS (Case2); or Pdr after Csr and CsrS (Case4).

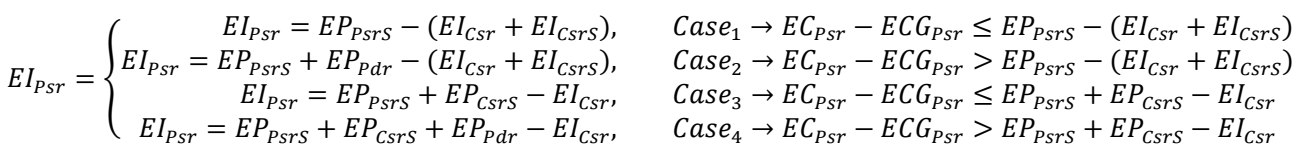

- Prosumers + Storage (PsrS): Psr after Csr and CsrS (Case1); Psr and Pdr after Csr and CsrS (Case2); Psr and CsrS after Csr (Case3); or Psr, CsrS and Pdr after Csr (Case4).

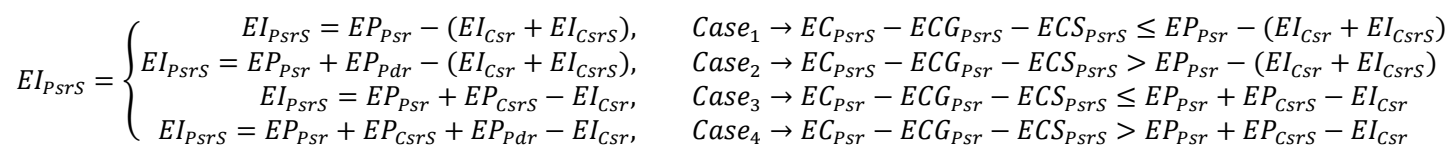

- Producers (Pdr): When the energy to be exported is greater than the energy generated locally (Case1); or when it is greater than locally generated and stored (Case2). 


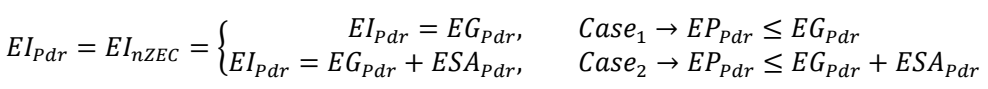

\subsection{Economic performance evaluation of Nearly Zero Energy Cities}

The economic evaluation of the nZEC is carried out with the subroutines that make up the EATEP in its configuration V: The Type EATEP-EEP to evaluate the nZEBs and/or the NZEBs and the nZEC itself, and the Type EATEP-EGP to evaluate the DG systems belonging to the Producers. The main indicator of the EATEP is the Global Cost (CG(T)), equations (6) and (7); its result is the net present value of three groups of costs for Prosumers (Psr), Consumers (Csr) and Producers (Pdr): Global Investment Cost $(\mathrm{CIG}(\mathrm{T}))$, Global Running Cost $(\mathrm{CRG}(\mathrm{T}))$ and Global Energy Cost (CEG(T)). CIG(T) and CRG(T) are calculated with equations (8) and (10) respectively, from the investment and Maintenance Cost (CM) of energy measures (Components $(j)$ ). In the calculation of $\mathrm{CIG}(\mathrm{T}), \mathrm{CII}(\mathrm{T})$ is the Initial Investment Cost of the Component $j$, and $\mathrm{Cl}(\mathrm{Tn})$ is the replacement cost where $t$ is equal to Lifespan (Tn) of each Component $j$, and $V F \_(T)$ is the final value in the year $T$ (equation (9) [24]). CEG(T), equations (11), (12) and (13), depend on the hourly energy flows $\left(\mathrm{FE}_{-} \gamma(\mathrm{h})\right)$, the tariffs for access to the distribution grids (PCharge_ $\gamma(h)$ to the power charges of access, and ECharge_ $\gamma(h)$ to the energy charges), and the economic value of the flow (EValue_ $\gamma(h))$ calculated based on market energy prices (PEU_Y $(h)$ ). In CEG(T), the income received by the Prosumers when exporting their energy surpluses to the grid are calculated as negative costs which help reduce $C G(T)$. Thus, EValue_ $\gamma(h))$ depends on whether FE_ $Y(h)$ is an amount of energy imported (consumed) or exported -equation (13)-: if it is imported, EValue_ $\gamma(\mathrm{h})$ is calculated as a cost, and if it is exported, it is calculated as a negative cost. Each of the future annual costs were updated to the initial year using the Discount Rate, $R d(t)$. This rate, equation (14), depends on the Real Interest Rate (RR), equation (15), and Inflation Rate (RI).

$$
\begin{aligned}
& C G_{(n Z E C)}(T)=C G_{(P s r)}(T)+C G_{(C S r)}(T)+C G_{(P d r)}(T) \\
& C G(T)_{(P s r, C S r, P d r)}=C I G(T)_{(P s r, C s r, P d r)}+C R G(T)_{(P s r, C s r, P d r)}+C E G(T)_{(P s r, C s r, P d r)}
\end{aligned}
$$




$$
\begin{aligned}
& C I G_{(P s r, C s r, P d r)}(\mathrm{T})=\sum_{j}\left[C I I(t=0)_{j}+\left(\sum_{t=1}^{T} C I_{j}\left(T n_{j}\right) \times R d_{t}(j)\right)-V F_{j}(T)\right] \\
& V F_{j}(T)=V I C_{j} \times\left(1+\frac{R X_{j}}{100}\right)^{\left(n_{T}(j) \times T_{n}(j)\right)} \times\left[\frac{\left(n_{T}(j)+1\right) \times T_{n}(j)-T}{T_{n}(j)}\right] \times R d_{j}(t) \\
& C R G_{(P r r, C S r, P d r)}(T)=\sum_{j}\left[\sum_{t=1}^{T} C R_{j}(t) \times R d_{t}(j)\right] \\
& C E G_{(\text {Endo_Psr, }, \text { Srr })}(T)=\sum_{\gamma}\left[\sum_{h=1}^{h=T \times 8760 \text { hours }}\left(\text { PCharge }_{\gamma}(h)+\text { EValue }_{\gamma}(h)\right) \times R d_{\gamma}(t)\right] \\
& C E G_{\left(E x p_{-} P s r, C S r\right)}(T)=\sum_{\gamma}\left[\sum_{h=1}^{h=T \times 8760 \text { hours }}\left(\operatorname{PCharge}_{\gamma}(h)+\operatorname{ECharge}_{\gamma}(h) \times F E_{\gamma}(h)+\operatorname{EValue}_{\gamma}(h)\right) \times R d_{\gamma}(t)\right] \\
& \text { EValue }_{\gamma}(h)=\left\{\begin{aligned}
F E_{\gamma}(h) \times P E U_{\gamma}(h), & \text { If } F E_{\gamma}(h) \text { is imported } \\
-F E_{\gamma}(h) \times P E U_{\gamma}(h), & \text { If } F E_{\gamma}(h) \text { is exported }
\end{aligned}\right. \\
& R d_{\gamma, j}(t)=\frac{1}{(1+R R / 100)^{t}}[-] \\
& R R=\frac{R-R I}{1+(R I / 100)}[\%]
\end{aligned}
$$

\section{Case study ${ }^{3}$ : the Nearly Zero Energy model for Barcelona}

Barcelona is a European city that is home to approximately $3.5 \%$ of the population of Spain. It is located on the coast of the Mediterranean Sea, covering an area of $102.159 \mathrm{~km}^{2}$, and presents ideal conditions for the use of solar energy: it has on average 2,477 hours of sunshine per year, which represents an average daily solar radiation of $1,502 \mathrm{kWh} / \mathrm{m}^{2}[60]$. The city has opted for growth and development under the concept of Smart City, which has led to specific plans to achieve its energy self-sufficiency [60-62]. According to the annual report of its Energy Agency in 2014 [63], Barcelona consumed a total of $15,627 \mathrm{GWh}$ of final energy, equivalent to $26,946.14 \mathrm{GWh}$ of primary energy, distributed in its economic sectors as follows: commercial and services $34.09 \%$, domestic $28.11 \%$, transport $25.65 \%$, industry $11.54 \%$, and other $0.61 \%$. The entirety of this consumption comes from natural gas, nuclear energy and liquid fuels. $29.7 \%$ of the electric energy was generated in the city itself, 4,865 GWh, mainly in combined cycle plants and less than $1 \%$ in installations that take advantage of the local renewable resources.

Following the guidelines of the nZEC-EATEP, in this case study we analysed the energy performance of six Packages of combinations between EEM and PV self-consumption systems installed in a portion of the city's buildings. The objective of this evaluation was to discover the scope of the nZEBs investment and the economic participation of Prosumers in the energy balance and selfconsumption of Barcelona. This was divided into i) three evaluation approaches, two based on the

\footnotetext{
${ }^{3}$ Several publications have reported the state of self-consumption in cities around the world: [71-73] in the United States, [74] in cities in Europe, [75] in cities in the Middle East, and [76] in Asian cities.
} 
variation of consumption of base energy for Consumers in the initial year, and one on the analysis of Prosumers; and ii) in three tariff scenarios with and without daily hourly discrimination to determine which combination of these energy measures would allow the reduction of the primary energy of the city at the lowest possible cost. The energy and economic characteristics of these six Packages were defined by comparing the information of two groups of public data of the buildings of Barcelona (data obtained from public administration entities in Barcelona and the Spanish Autonomous Community of Catalonia). The data detailed i) the economic and technical characteristics of EEM of different types of buildings in the city, and ii) the economic and technical characteristics of the PV generation capacity of the city's rooftops.

\subsection{Configuration of the initial data}

The case study was evaluated by simulating a period of 37 years (T), from 2013 (year of the initial investment) to 2050 ; with R equal to $4 \%$, and RI equal to $2 \%$. Based on the data groups i) and ii), we built a community of Prosumers, a group of Consumers, and a DG system that replaces the operation of Producers (only in the activity of local generation). Figure 3 describes the distribution of these groups, whose characteristics are:

- Prosumers (Psr): hypothetical community of subgroups of Prosumers buildings (nZEB without energy storage) of 2, 3, 4, 5 and 6 floors, whose investment in EEM and PV selfconsumption and whose electric energy generated is called Endogenous 1 (Endo_1).

- Consumers (Csr): electric energy consumption sectors of the City (without energy storage), evaluated according to two different approaches (described below).

- DG-Extra: a group of rooftops with investment of PV generation systems on them (PV-Extra), whose generated electric energy is called Endogenous 2 (Endo_2).
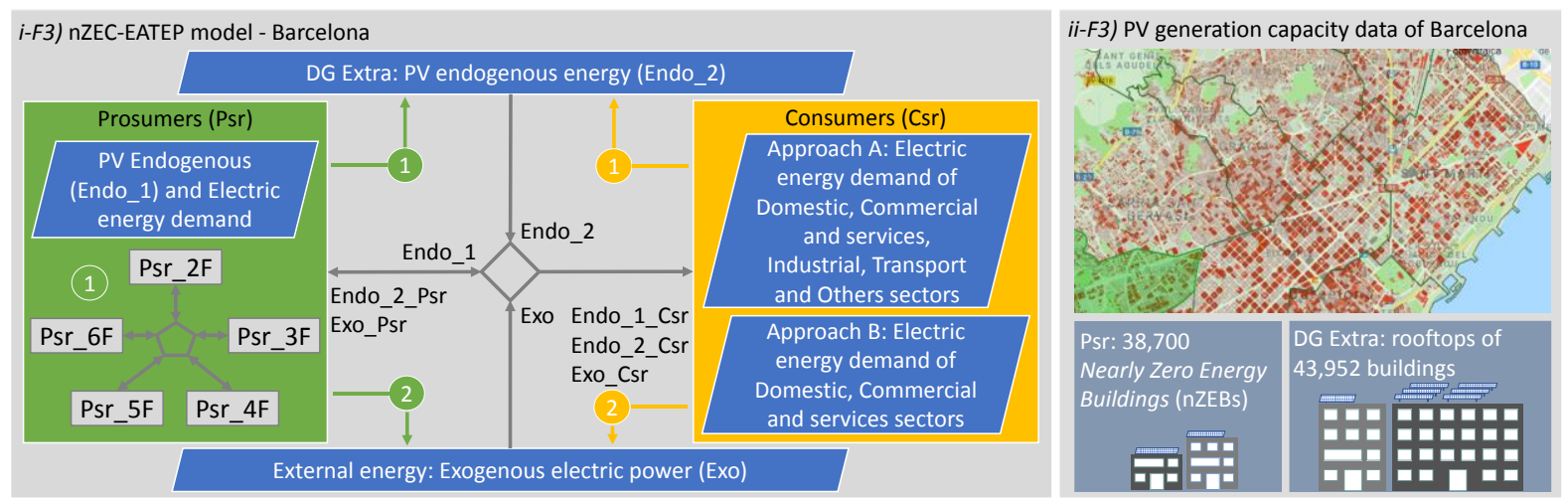

Figure 3. Case study: the Nearly Zero Energy model for Barcelona. Note: i-F3) nZEC-EATEP model - Barcelona, Energy cost 1) eq. (11) and 2) eq. (12); ; ii-F3) PV generation capacity data of Barcelona, Source: Adapted from $[64,65]$ 
The evaluated Packages were composed of the EEM packages (Packages-EEM) presented in the [66] (ICAEN-Study), and the PV capacity data of Barcelona presented in $[64,65]$ (PV-Map). The data from these sources were cross-referenced with the relation of the number of floors of the buildings they studied. The objective was to define the initial data on the electric energy consumption of Prosumers and Consumers, the capacity of energy saving and PV self-consumption in the Prosumers, and the extra PV generation capacity corresponding to PV-Extra. Due to the fact that it has not been possible to determine the sector to which the buildings studied in the PV-Map belong, it was assumed that the buildings theoretically characterized in the ICAEN-Study include the buildings presented in this first source. As a result, and as shown in Table 1, for the scope of this paper, a total of 86,626 buildings with suitable PV generation capacity were included in the calculation of the Global Cost of the nZEC-EATEP model. Of this total, buildings from 2 to 6 floors of the ICAEN-Study were assumed as buildings of Prosumers. The remaining number of buildings were considered as buildings of the residential, commercial, industrial and service sectors of Barcelona ${ }^{4}$. Finally, the consumption of initial electric energy assumed for the Consumers was the consumption of this energy vector in the city in 2014 minus the consumption of the Prosumers.

Table 1. Distribution of buildings evaluated in Prosumers, Consumers and PV_Extra. Source: [64-67].

\begin{tabular}{|c|c|c|c|c|c|}
\hline & $\begin{array}{l}\text { COD | Subtotal } \\
\text { | Total }\end{array}$ & No. of floors & Type of building 5 & No. of buildings & $\begin{array}{l}\text { Electric energy } \\
\text { consumption } \\
\text { [GWh/Year] }\end{array}$ \\
\hline \multirow[t]{6}{*}{ Prosumers } & $2 \mathrm{~F}$ & 2 & $A, B$ and $C$ & 12,463 & 61.787 \\
\hline & $3 F$ & 3 & $\mathrm{D}$ & 6,238 & 41.853 \\
\hline & $4 \mathrm{~F}$ & 4 & 1 & 4,842 & 245.457 \\
\hline & $5 F$ & 5 & $\mathrm{E}$ and $\mathrm{H}$ & 7,082 & 339.516 \\
\hline & $6 F$ & 6 & $F$ and $G$ & 8,075 & 274.779 \\
\hline & Subtotal & N/A & N/A & 38,700 & 969.363 \\
\hline \multirow[t]{2}{*}{ Consumers } & Approach A & N/A & N/A & N/A & $5,771.847$ \\
\hline & Approach B & N/A & N/A & N/A & $3,225.927$ \\
\hline \multirow[t]{7}{*}{ PV_Extra } & N/A & No data & N/A & N/A & N/A \\
\hline & N/A & 1 & N/A & 2,135 & N/A \\
\hline & N/A & 7 & N/A & 5,564 & N/A \\
\hline & N/A & 8 & N/A & 3,606 & N/A \\
\hline & N/A & 9 & N/A & 3,266 & N/A \\
\hline & N/A & $\geq 10$ & N/A & 3,636 & N/A \\
\hline & Subtotal & N/A & N/A & 43,952 & N/A \\
\hline \multicolumn{2}{|c|}{ Total, Approach A } & N/A & N/A & 82,652 & $6,735.24$ \\
\hline \multicolumn{2}{|c|}{ Total, Approach B } & N/A & $\mathrm{N} / \mathrm{A}$ & 82,652 & $4,189.32$ \\
\hline
\end{tabular}

\footnotetext{
${ }^{4}$ The data on the number of buildings determined for the Prosumers are consistent with the Census 2011 of Spain in Barcelona. See Buildings with houses according to floors above ground by districts. 2011 [67].

${ }^{5}$ Type of buildings:

- $\quad$ Single family detached house: A, built before 1951; B, built between 1951 and 1980; C, built between 1981 and 1990; D, built after 1990.

- Multi-family building: E, built before 1951; F, built between 1951 and 1980 with collective boiler; G, built between 1951 and 1980 without collective boiler; H, built between 1981 and 1990; I, built after 1990.
} 


\subsection{Packages evaluated}

The initial data of the Packages-EEM obtained for the Prosumers are presented in Table 2, and the Components that make up these Packages are as follows. The number in brackets is the number of years of useful life with which they were evaluated.

- Package 1 (Pg 1): Exterior façade insulation (50 years) + interior roof insulation (50 years) + PVC windows and low emissive glass (N/A).

- Package 2 (Pg 2): Interior façade insulation (50 years) + interior roof insulation (50 years) + PVC windows and low emissivity glass (N/A).

- Package 3 ( $\mathrm{Pg} 3$ ): Façade insulation in the chamber (50 years) + interior cover insulation (50 years) + PVC windows and low emissive glass (N/A).

- Package 4 (Pg 4): Exterior façade insulation (50 years) + exterior covered insulation (50 years) + PVC windows and low emissivity glass (N/A).

- Package 5 (Pg 5): Integral rehabilitation; EPS 2.36 inches exterior façade insulation (50 years), MW 3.15 inches interior cover insulation (50 years), boiler renovation (16 years), PVC frame windows and 4/16/4 BE glass (N/A).

- Package 6 (Pg 6): Low cost measures; Adhesive tapes and elastic putty (10 years) + DHW aerators and flow reducers ( 30 years) + LED lighting ( 20 years).

Table 2. Initial data of EEM for the evaluated Packages. Note: The initial investment cost only refers to the cost of energy rehabilitation. Source: [66]

\begin{tabular}{|c|c|c|c|c|c|c|c|}
\hline \multirow[t]{2}{*}{ Item } & \multirow[t]{2}{*}{ Prosumer } & \multicolumn{6}{|l|}{ Packages } \\
\hline & & Pg 1 & Pg 2 & $\mathrm{Pg} 3$ & $\mathrm{Pg} 4$ & $\operatorname{Pg} 5$ & Pg 6 \\
\hline \multirow[t]{5}{*}{ Energy savings [\%] } & $2 F$ & 43.97 & 19.2 & NA / NS & NA / NS & 53.73 & 6.43 \\
\hline & $3 F$ & 35.5 & 15.5 & 15.1 & 36.1 & 44.6 & 6.2 \\
\hline & $4 \mathrm{~F}$ & 31.6 & 14.3 & 13.7 & 32.1 & 41.6 & 6.8 \\
\hline & $5 F$ & 41.4 & 18.75 & NA / NS & 41.8 & 51.1 & 6.95 \\
\hline & $6 \mathrm{~F}$ & 47.25 & 20.7 & 21.5 & 47.6 & 59 & 7.35 \\
\hline CII_EEM [M€] & Total & $2,348.626$ & $1,971.504$ & $1,364.605$ & $2,192.395$ & $2,209.692$ & 52.547 \\
\hline CM_EEM [M€/Year] & Total & 36.228 & 20.260 & 34.566 & 36.228 & 36.228 & 36.228 \\
\hline
\end{tabular}

Regarding the PV generation capacity of the buildings selected from the PV-Map, Table 3 presents the initial data that make up the six Packages which have been evaluated. This study uses panels of $270 \mathrm{~W}$ of $2 \mathrm{~m}^{2}$ and generated energy calculated as a mean value $1,250 \mathrm{kWh} / \mathrm{kWp} \cdot Y$ ear.

Table 3. Initial data of PV systems for the evaluated Packages. Source: [65]. Notes: *Endo_1; **Endo_2; ***Total Endo.

\begin{tabular}{llllll}
\hline Generation & Useful surface $\left[\mathrm{km}^{2}\right]$ & Power $[\mathrm{MW}]$ & $\begin{array}{l}\text { Generation capacity } \\
{[\mathrm{GWh} / \text { Year] }}\end{array}$ & CII [M€] & CM [M€/Year] \\
\hline Prosumers & 1.924 & 181.823 & $227.301^{*}$ & 636.443 & 8.835 \\
PV_Extra & 3.307 & 312.509 & $390.665^{* *}$ & $1,093.861$ & 10.641 \\
Total & 5.231 & 494.332 & $617.966^{* * *}$ & $1,730.304$ & 19.476 \\
\hline
\end{tabular}




\subsection{Tariff scenarios and energy consumption approaches evaluated}

\subsubsection{Tariff scenarios}

We evaluated the nZEC-Model of Barcelona using three electric tariffs access to the grid in Spain, presented in [66,68], and the prices of energy in the Iberian market presented in [69]. These tariffs include a fixed charge and a variable charge for energy, which are different for Consumers and Prosumers. In the case of the latter, the fixed charge covers the bidirectional operation of the import and export of electricity. The future value of these access tariffs was calculated using an annual evolution rate $(\mathrm{RX})$ of $1.575 \%$, resulting from the average of the Consumer price index (CPI) for the period 2017-2022 in Spain. Regarding the price of energy, we use the hour profile of a model year built with the average of the prices of the period 2014-2017.

For Prosumers, as residential buildings, low voltage and power tariffs ( $<10 \mathrm{kV}$ and $\leq 10 \mathrm{~kW}$ ) were used, assuming an access power of $4.6 \mathrm{~kW}$. This value is in accordance with the average consumption of the dwellings of the buildings characterized in the ICAEN-Study. In Scenario 1 (S1) a flat tariff was used. In Scenario 2 (S2) a tariff of two intraday periods of hourly discrimination was used. And in Scenario 3 (S3) a tariff of three periods of discrimination was used ${ }^{6}$. Table 4 presents the values of these tariffs in their power and energy charges. For Consumers, tariffs with and without periods of hourly discrimination of power access of less than $1 \mathrm{kV}$ and up to $36 \mathrm{kV}$ and with a lower power of $10 \mathrm{~kW}$ and up to $450 \mathrm{~kW}$ were used. In each of these tariffs we assume a hypothetical access power to calculate a single access power to the grid of $11.8167 \mathrm{~kW}$ for all buildings of the Consumers. Because the objective of this paper was to study the economic performance of Prosumers, the same electric energy tariff was used for the Consumers in the three scenarios evaluated. Table 5 presents the value of the power and energy charges calculated for Consumers.

Table 4. Tariffs of electric energy used for Prosumers in each of the scenarios evaluated. Source: [68]. Note: *Denomination used in Spanish electric system; Winter (W); Summer (S).

\begin{tabular}{lllll}
\hline Scenario & Tariff* & Period (Hours) & Power Charge [€/Year] & Energy Charge [€/kWh] \\
\hline 1 & 2.0A & Flat & 174.999759 & 0.044027 \\
2 & 2.0DHA & P1 (W: $12-22 ; \mathrm{S}: 13-23)$ & 174.999759 & 0.062012 \\
& & P2 (W: 22-12; S:23-13) & 174.999759 & 0.002215 \\
3 & 2.0DHS & P1 (13-23) & 174.999759 & 0.074568 \\
& & P2 (23-1) & 174.999759 & 0.017809 \\
& & P3 (1-7) & 174.999759 & 0.006596 \\
\hline
\end{tabular}

\footnotetext{
${ }^{6}$ The tariff of three periods of hourly discrimination, called super-valley, was designed in the Spanish electricity market with the purpose of promoting the introduction of the electric vehicle. This tariff allows, at a low cost, users to recharge the batteries of this type of vehicle at night, after 10 or $11 \mathrm{pm}$ and on into the early hours of the morning.
} 
Table 5. Tariffs of electric energy used for Consumers in all scenarios evaluated. Note: Tariffs and access powers assumed, according to the denomination of the electric market in Spain: 2.0A [4.6kW], 2.0DHA [4.6kW], 2.0DHS[4.6kW], 2.1A [10.35kW], 2.1DHA [10.35kW], 2.1DHS [10.35kW], 3.0A [15kW], 3.1A [26kW]. Source: Based on [70].

\begin{tabular}{llllll}
\hline Winter & \multicolumn{5}{c}{ Summer } \\
\hline Period (Hours) & $\begin{array}{l}\text { Power Charge } \\
{[€ / \text { Year] }}\end{array}$ & $\begin{array}{l}\text { Energy Charge } \\
{[€ / \mathrm{kWh}]}\end{array}$ & Period (Hours) & $\begin{array}{l}\text { Power Charge } \\
{[€ / \text { Year] }}\end{array}$ & $\begin{array}{l}\text { Energy Charge } \\
{[€ / \mathrm{kWh}]}\end{array}$ \\
\hline $1-2$ & 455.5225946 & 0.022218 & $1-2$ & 455.5225946 & 0.022218 \\
$2-8$ & 401.9505098 & 0.017808 & $2-8$ & 401.9505098 & 0.017808 \\
$8-10$ & 401.9505098 & 0.020611 & $8-9$ & 401.9505098 & 0.020611 \\
$10-13$ & 455.5225946 & 0.022218 & $9-10$ & 443.4905825 & 0.021230 \\
$13-14$ & 455.5225946 & 0.037364 & $10-11$ & 455.5225946 & 0.022218 \\
$14-19$ & 455.5225946 & 0.051554 & $11-12$ & 489.0270513 & 0.022415 \\
$19-20$ & 489.0270513 & 0.051752 & $12-13$ & 513.0910991 & 0.023189 \\
$20-23$ & 513.0910991 & 0.052525 & $13-14$ & 513.0910991 & 0.038335 \\
$23-24$ & 513.0910991 & 0.037378 & $14-16$ & 513.0910991 & 0.052525 \\
$24-1$ & 455.5225946 & 0.022218 & $16-17$ & 489.0270513 & 0.051752 \\
- & - & - & $17-24$ & 455.5225946 & 0.051554 \\
- & - & - & $24-1$ & 455.5225946 & 0.022218 \\
\hline
\end{tabular}

\subsubsection{Energy consumption approaches}

The nZEC-Model to Barcelona was evaluated according to three different approaches based on the consumption of electric energy of the city. The first of these approaches (Approach A) was configured based on the consumption of the domestic, commercial and services, industrial, transport and other sectors. The second approach (Approach B) was configured based on the consumption of the domestic and commercial sectors and services (62.2\% of total consumption). And the third approach (Approach C) focused on the consumption of the Prosumers, thus analysing the investment towards nigh zero-energy consumption of a community of buildings within the city.

\subsection{Profiles of electric energy consumption and PV generation designed}

The profiles of electric energy consumption and PV generation that were used in the model were constructed based on the data of 2014-2017 hourly intervals of mainland Spain, presented in [69]: the total consumption to construct the profile of the Consumers, and consumption data in low voltage to construct the profile of the Prosumers.

\section{Results}

\subsubsection{General results}

Taking into account that this economic evaluation addressed the utilization of the PV generation capacity of $34.7 \%$ of the Barcelona's rooftops ( 82,652 of a total of 238,213 included in the Map), and 
the investment in EEM and PV self-consumption (with capacity of export of surpluses to the grid) in $17 \%$ of its buildings, the main results are:

- On the basis that the city consumes between 6,700 and 7,000 GWh of electricity per year, it has the capacity to reduce the primary energy demanded by between 3.41 and $9.68 \%$. This can cause a reduction of between $4.16 \%$ and $12.25 \%$ in energy costs, and between $5.16 \%$ and $11.43 \%$ in $\mathrm{CO}_{2}$ emissions.

- The investment required to generate these savings is 1.25 and 1.32 times the energy costs of the city over a period of 37 years, taking into account that this investment covers the initial value and the replacement of the technical components of the packages during the same period.

- The Package of general rehabilitation of the studied buildings (Package 5) obtains the best results in terms of reduction of primary energy consumption and $\mathrm{CO}_{2}$ emissions, as well as in energy costs.

- The low-cost Package (Package 6) obtained the Optimal-Cost from the Global Cost study due to its low investment and maintenance costs. But in terms of energy costs, the general rehabilitation Package (Package 5) allows for better results (almost $8 \%$ less).

- The scenario of tariffs for three periods of intraday and hourly discrimination gave a better result for the Global Cost.

- Regarding the results of the approach of the Prosumers (Approach C), this community can reduce its primary energy consumption by up to $51 \%$, up to $70 \%$ of the $\mathrm{CO}_{2}$ emissions, and between $32 \%$ and $71.25 \%$ of its energy costs.

\subsubsection{Consumption and generation profiles}

In the graphics $i-F 4$ ) and $i i-F 4$ ), Figure 4 presents the profiles resulting from the average of the 37 years of economic evaluation of the consumption of Consumers and Prosumers and the generated endogenous energy. In the case of the Consumers, their consumption is presented in the approaches A and B. In that of the Prosumers, the consumption profile of the Reference Case is presented and after the savings achieved with the six Packages are evaluated. From top to bottom, these Packages are ranked from lower (Package 6: low cost measures) to higher savings achieved (Package 5: complete building rehabilitation). The same graphs present the average profiles of generation Endo 1 (Prosumers only), Endo 2 (PV_Extra only), and the sum of these two (T. Endo). The graph ii-F4) presents the daily profiles of consumption and generation. As shown here, the Endo 1 energy, at its generating peak, (between 12 and $3 \mathrm{pm}$ ) exceeds the second consumption peak of the Prosumers 
with Packages 4, 1 and 5. In total during the evaluation period, Endo 1 covered $22.37 \%$ of the demand of the Prosumers Reference Case, and Endo 2 covered $6.73 \%$.

$i$-F4) Daily average of the annual profile

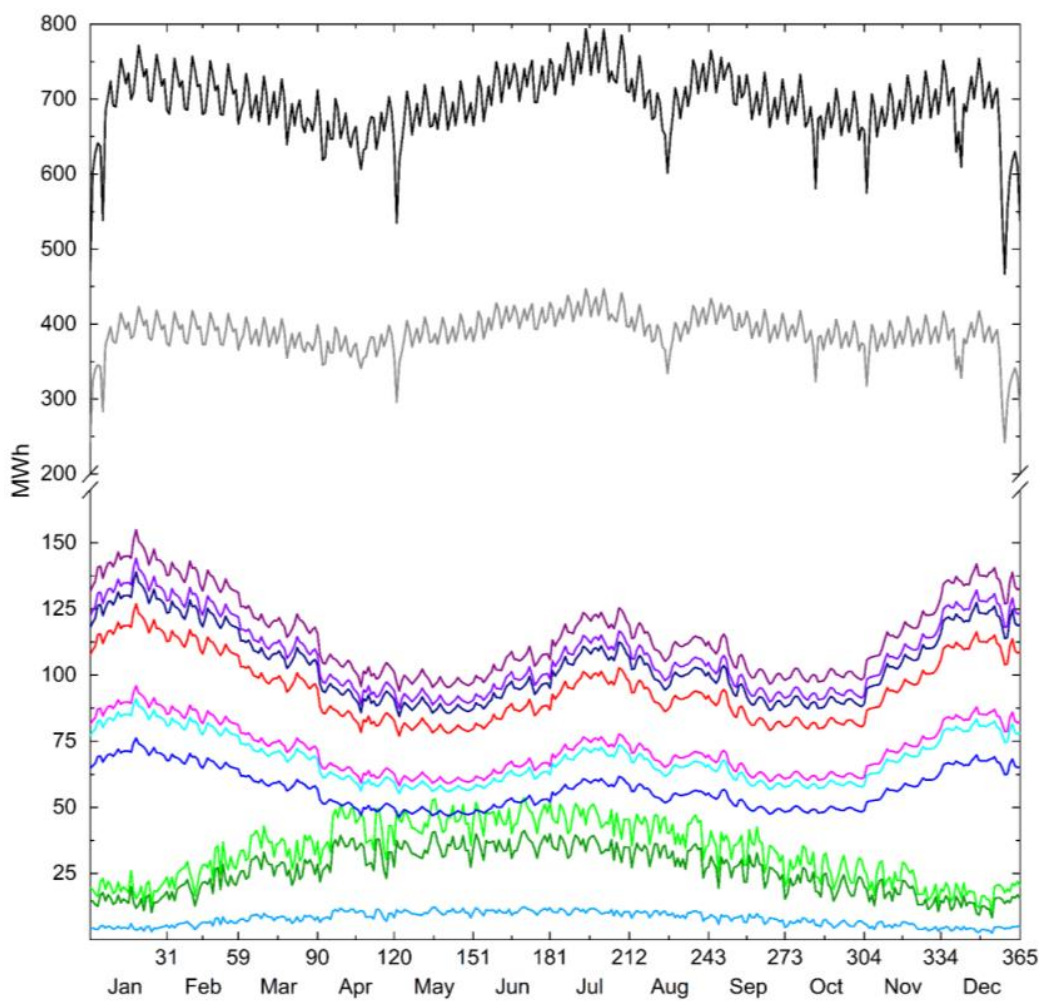

ii-F4) Hourly average of the daily profile

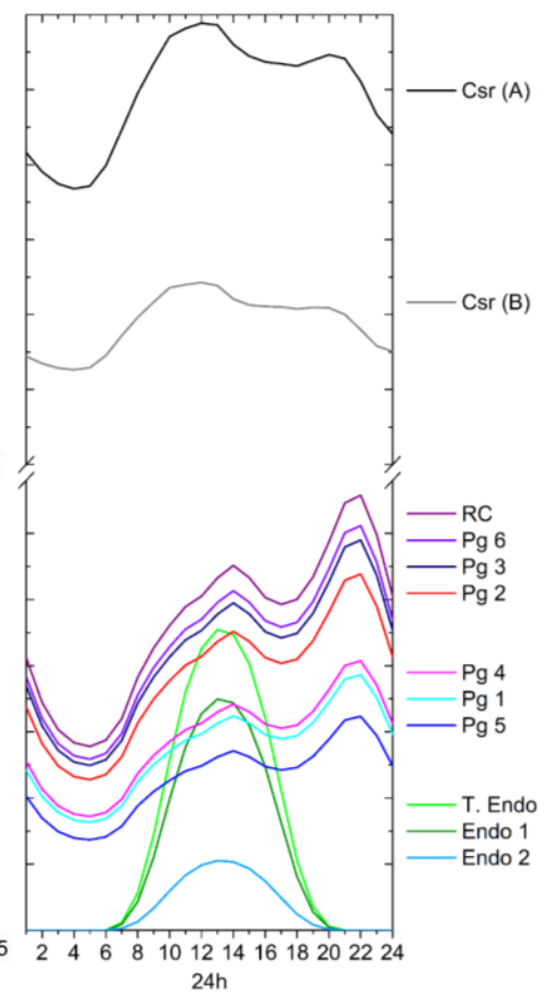

Figure 4. Profiles resulting from the average of the 37 years of economic evaluation. Note: Consumers (Csr); Reference Case (RC); Approaches A (A) and B (B); Package 6 (Pg 6): Low cost measures; Package 5 (Pg 5): Complete building rehabilitation.

\subsubsection{Global Cost and Optimal-Cost}

Figure 5 presents the results of the Global Cost (CG(T)) and the Global Primary Energy Consumed $(E G C(T))$ in the graphical format of the Optimal-Cost. Graph $i-F 5)$ presents the results of the approaches A and B, and Graph ii-F5) presents the results of approach C. In the two graphs the packages are ordered from right to left according to the consumption of primary energy of the nZECModel. In these results, with the exception of Package 2, the Global Cost increases in with energy saving due to the packages costs. Approaches A and B share the same results in Global Investment and Running Costs, which were not accounted for in their respective reference cases. The difference in the Global Cost between these two approaches is therefore due to the energy costs: Approach A analyses the coverage of the electric energy demand of the whole city, and Approach B focuses on a demand $37.8 \%$ lower (energy consumption of the domestic and commercial sectors and services). 
The energy saving obtained with the packages of EEM and PV self-consumption is crucial in reducing the Global Cost of the model. Moreover, with each electric energy tariff scenario each Package gives a different Global Cost: the lowest result is obtained with the tariff of three periods of hourly discrimination (S3), followed by the results of the tariff with two periods (S1). However, in the Reference Case the two-period tariff allows obtaining the lowest Global Cost.
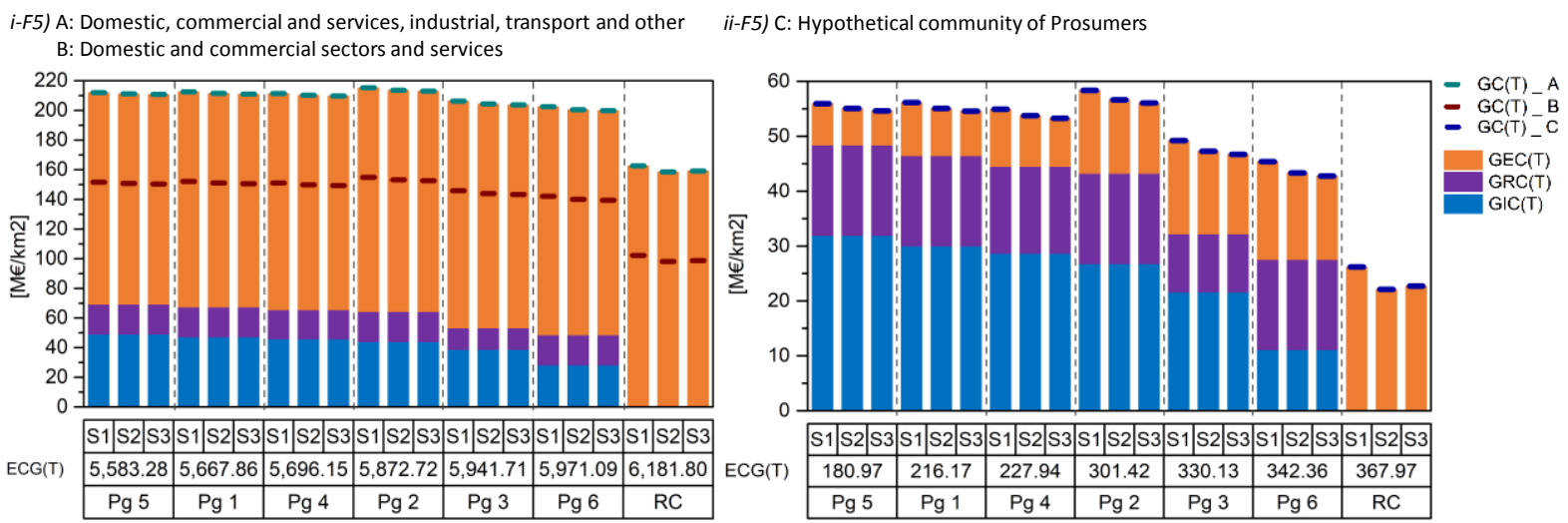

Figure 5. Optimal-Cost graphics. Notes: $T=37$ years; Reference Case (RC); Global Cost (CG(T)); Global Primary Energy Consumed (ECG(T)) [GWh_PE/km2].

\subsubsection{Analyses of the energy, economic and environmental benefits}

To analyse the benefits obtained with the Packages in more detail, the Effect-Index [23] indicator was calculated. This indicator is the sum of the energy, economic and environmental benefits normalized between 0 and 1 . Therefore, its result is higher if the energy saving and reduction of $\mathrm{CO}_{2}$ emissions are greater and energy costs are lower. Figure 6 compares the results of Effect-Index with the results of the Global Energy Cost (CEG(T)). Unlike the approaches $A$ and $B$, in the approach $C$ the lower CEG (T) obtained in the scenario with three periods of hourly discrimination (S3) allows obtaining a greater result in the Effect-Index. This is because in this approach the economic results of the energy exported by the Prosumers stand out without the results of the Consumers. 


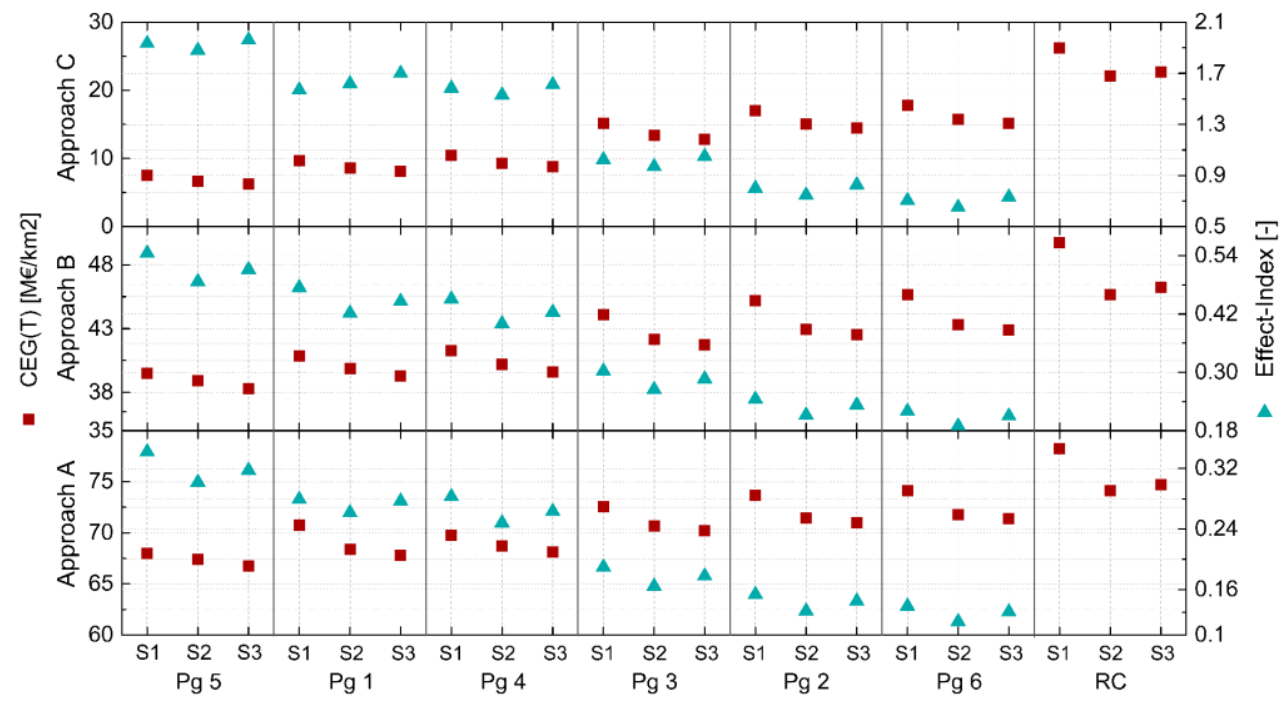

Figure 6. Global Energy Cost (CEG(T)) and Effect-Index by Packages and Scenarios in each evaluation approach.

\subsubsection{Analysis of tariffs on the cost of energy}

As seen above, the Package of general rehabilitation (Package 5) obtained the most outstanding results in the Optimal-Cost, and the greatest economic benefit was obtained in the scenario with three periods of hourly discrimination (S3). From this, Figure 7 presents the annual average hourly energy performance profile of this package. With a ratio between exported and imported energy (EP/EI) of 0.31 in all scenarios, Scenario 3 presented a ratio between costs of exported and imported energy (CE/IR) of 0.34 versus 0.26 and 0.31 in Scenarios 2 and 1 respectively. The greatest volume of income from the export of energy (negative costs) occurred in the months of the middle of the year, when the energy surpluses of self-consumption are higher. 


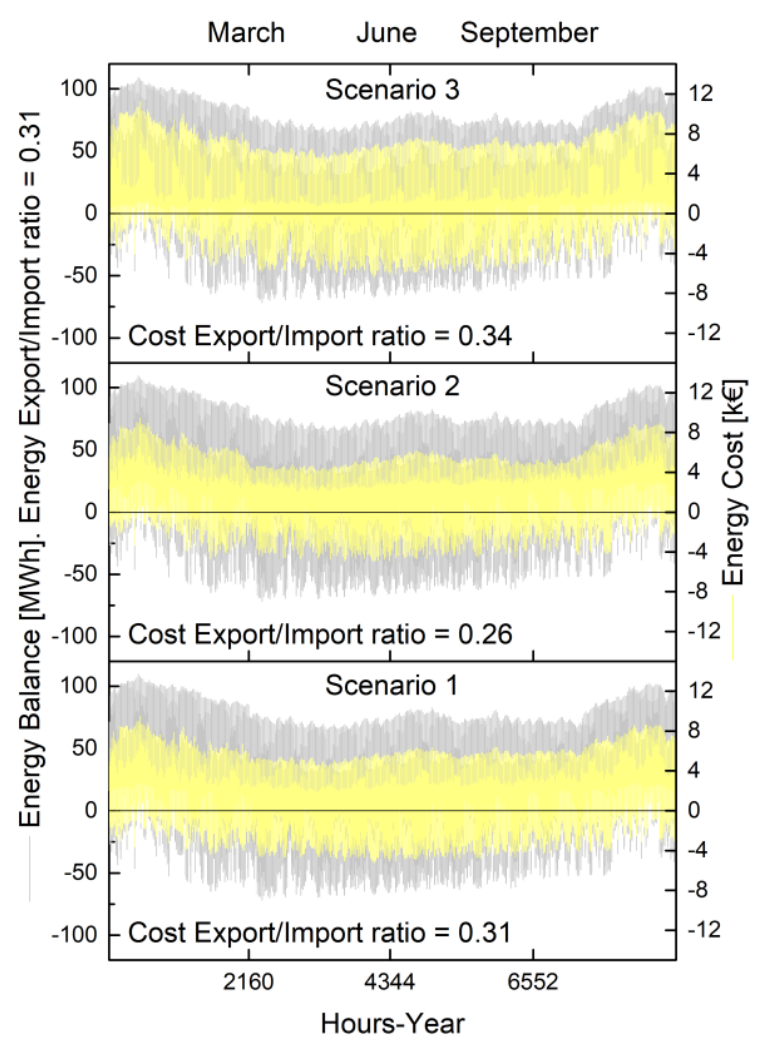

Figure 7. Hourly average of the annual profile of the energy balance vs energy costs (positives and negatives) of the Prosumers community (approach C) with the energy savings of the Package 5 in the tariffs scenarios 1 (S1), 2 (S2) and 3

(S3).

Figure 8 extends this analysis by presenting the hourly average of the daily profile in winter and summer, indicating the start of the intraday periods of tariffs: P1 (peak), P2 (valley) and P3 (supervalley). In the tariff without hourly discrimination (S1), graph $i$-F8), the costs (positives and negatives) follow the same curve as the energy balance: their ratios $E P / E I$ and $C E / I R$ are equal to 0.27. Compared to $\mathrm{S} 1, \mathrm{~S} 2$ and $\mathrm{S} 3$, graph ii-F8), handle different energy and cost balances because the periods of hourly discrimination are different in winter and summer. In these two scenarios, the energy balance in winter obtained an EP/El equal to 0.1 , and of 0.52 in summer; values that differ due to the variation of the energy import depending on the PV generation between these two seasons. However, the EC/IR is higher with the tariffs of three periods of hourly discrimination that were studied in S3: 0.09 in winter and 0.64 in summer, compared to 0.08 in winter and 0.43 in summer in S2. As shown in the graph, this result is due to the fact that there is a marked difference in the $\mathrm{S} 3$ between the costs of the morning, those of midday, and those of the evening. 
i-F8) S1: Flat tariff

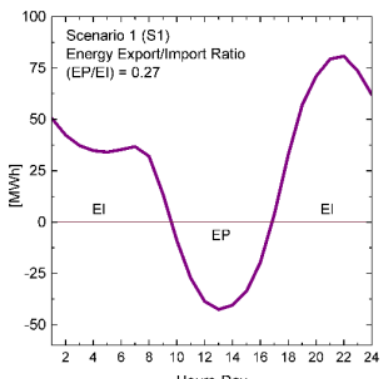

Hours-Day

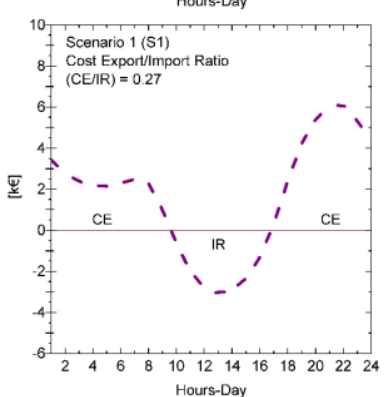

ii-F8) S2: Peak and Valley intraday periods; S3: Peak, Valley and Super valley intraday periods

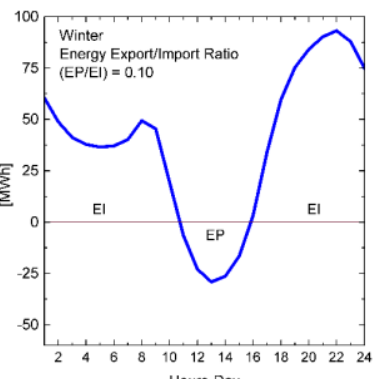

Hours-Day

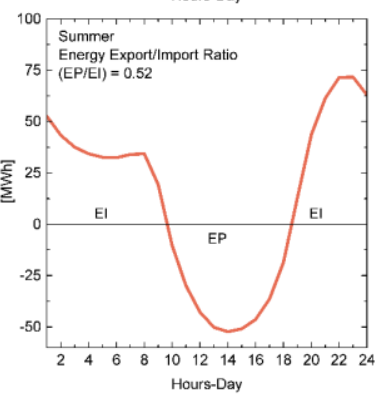

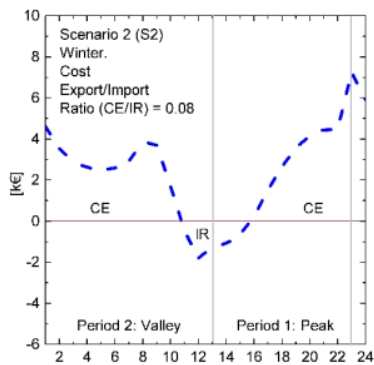

Hours-Day

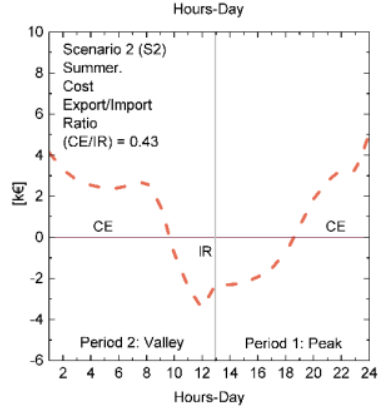

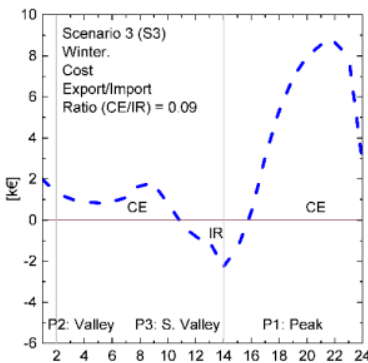

Hours-Day

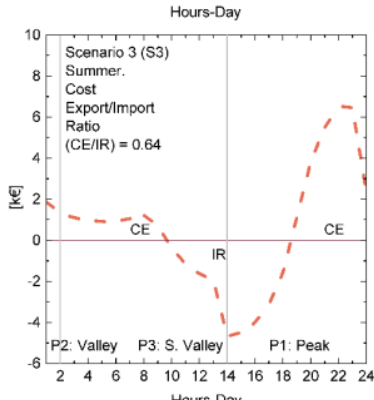

Figure 8. Hourly average of the daily profile of the energy balance and the energy costs (positives and negatives) of Prosumers community (approach C) with the energy savings of the Package 5 in the tariffs scenarios 1 (S1), 2 (S2) and 3

(S3).

\section{Conclusions}

Faced with the emission of greenhouse gases due to covering the energy demand of cities with fossil energy resources, the urban energy transition is crucial in order to be able to achieve climate objectives against global warming. This transition process aims to use renewable energy resources in cities while reducing the consumption of external energy resources of fossil origin.

Although each city has different conditions, any use of local energy resources will reduce the consumption of primary external energy of fossil origin. However, investment, maintenance and energy costs are yet to be determined. This is the basis upon which the model proposed in this paper and the study from which its results are presented. In this context, this paper proposes a novel model to technically and economically evaluate the energy self-sufficiency of these urban areas. This model contributes by proposing the scalability in the simulation of Nearly Zero Energy Buildings up to Nearly Zero Energy Cities scale.

Using public data from Barcelona, this model was applied to the self-consumption study of this city. The objective was to analyse the scope of the investment in the PV self-consumption of buildings in order to promote the creation of communities of Prosumers within the cities. In order to do so, we studied the investment of six packages of energy rehabilitation measures and PV self-consumption in 38,700 buildings (2-6 floors), the investment in PV systems in the remaining 43,952 buildings 
(53.18\%), and we simulated 37 years (2013-2050) of the energy performance of this city. The results indicated that the existence of communities of nearly zero energy buildings sharing energy as Prosumers helps reduce primary energy consumption and $\mathrm{CO}_{2}$ emissions of the city. Regarding the results obtained in the specific evaluation conditions of the nZEC model for Barcelona, it is concluded that the general rehabilitation Package (Package 5) presents better results in terms of reduction of primary energy and energy costs and the tariff of three periods of intraday discrimination allows greater benefits for PV self-consumption than the flat tariff and the two-period tariff.

Within the process of energy transition, urban electrical systems go through a stage of digitalization that seeks to make their operation more flexible by involving consumers in the management of demand. Likewise, the urban energy transition includes new services in the cities, such as the aggregation of demand and the participation of Producers in distributed generation. By taking advantage of the Nearly Zero Energy Cities evaluation model presented here, the inclusion of these new characteristics of the electric urban systems will form the basis of any future work in the research area of this paper.

\section{Acknowledgements}

We are grateful for the support of the Foundation for Energy and Environmental Sustainability (FUNSEAM) in Barcelona, Spain, during this research. In particular, to its General Director, PhD in economics, Joan Batalla.

\section{References}

[1] UN Habitat. World Cities Report 2016 - Urbanization and Development: Emerging Futures. 2016th ed. Nairobi, Kenya: United Nations Human Settlements Programme (UN-Habitat); 2016. doi:10.1016/S0264-2751(03)00010-6.

[2] IRENA. Renewable Energy in Cities. IRENA - Int Renew Energy Agency 2016:64.

[3] United Nations. World Population Prospects The 2017 Revision Key Findings and Advance Tables. World Popul Prospect 2017 2017:1-46. doi:10.1017/CBO9781107415324.004.

[4] United Nations. World Urbanization Prospects: The 2018 Revision, Key Facts. 2018. doi:(ST/ESA/SER.A/366).

[5] Kammen DM, Sunter DA. Urban Planet: City-integrated renewable energy for urban sustainability. Science (80- ) 2016;352:922-8. doi:DOI: 10.1126/science.aad9302.

[6] Hauff J, Bode A, Neumann D, Haslauer F, Azevedo C, Haischer P, Hartmann B, Oswald K, Santos F, Sprott M, Schiffer H-W, Kaim-Albers N. Global Energy Transitions. Berlin, Germany: 2014.

[7] International Energy Agency. Perspectives for the energy transition: the role of energy efficiency. 2018th ed. Paris, France: International Energy Agency IEA/OECD; 2018.

[8] Check R, Space-based PS, Percent K, Shingles E. The Future of Solar Energy. Mit 2015:3-6. 
doi:10.1002/yd.20002.

[9] WEF. Energy Vision 2013 Energy transitions : Past and Future. World Econ Forum 2013:22. doi:070113.

[10] International Energy Agency (IEA). World Energy Outlook 2017. 2017th ed. Paris: IEA Publications; 2017.

[11] European Commission. Communication From the Commission To the European Parliament and the Council. The Road from Paris. 2016.

[12] OECD/IEA, IRENA. Perspectives for the Energy Transition: Investment Needs for a Low-Carbon Energy System. 2017.

[13] IRENA O and R. Renewable Energy Policies in a Time of Transition. 2018.

[14] REN21. Renewables 2016 Global Status Report. 2016. doi:ISBN 978-3-9818107-0-7.

[15] Parag Y, Sovacool BK. Electricity market design for the prosumer era. Nat Energy 2016:16032. doi:10.1038/nenergy.2016.32.

[16] Carlisle N, Geet O Van, Pless S. Definition of a " Zero Net Energy " Community. Natl Renew Energy Lab 2009:1-14.

[17] Managan K. Net Zero Communities: One Building At a Time. ACEEE Summer Study, 2012, p. 180-192.

[18] Mohamed A, Hasan A, Sirén K. Fulfillment of net-zero energy building (NZEB) with four metrics in a single family house with different heating alternatives. Appl Energy 2014;114:385-99. doi:10.1016/j.apenergy.2013.09.065.

[19] Hasan A, Mohamed A, Mohamed H. Net- and Nearly- Zero Energy Buildings : A Review of the Definitions and Case Studies . Proc. Sixth Int. Conf. Heating, Vent. Air-Conditioning, 2015.

[20] Visa I, Duta A, Moldovan M, Burduhos B. Implementing Renewable Energy Systems in Nearly Zero Energy Communities, 2017, p. 3-26.

[21] Amado M, Poggi F, Amado AR, Breu S. E-city web platform: A tool for energy efficiency at urban level. Energies 2018;11. doi:10.3390/en11071857.

[22] Amado M, Poggi F, Amado AR, Breu S. A cellular approach to Net-Zero energy cities. Energies 2017;10. doi:10.3390/en10111826.

[23] Villa-Arrieta $M$, Sumper A. A model for an economic evaluation of energy systems using TRNSYS. Appl Energy 2018;215:765-77. doi:10.1016/j.apenergy.2018.02.045.

[24] European Union. Directive 2010/31/EU of the European Parliament and of the Council of 19 May 2010 on the energy performance of buildings (recast). Off J Eur Union 2010:13-35. doi:10.3000/17252555.L_2010.153.eng.

[25] European Union. Commission Delegated Regulation (EU) No 244/2012 of 16 January 2012 supplementing Directive 2010/31/EU of the European Parliament and of the Council on the energy performance of buildings by establishing a comparative methodology framework for calculating. Off J Eur Union 2012:28. doi:10.3000/1977091X.C_2012.115.eng.

[26] Lolli F, Ishizaka A, Gamberini R, Rimini B, Balugani E, Prandini L. Requalifying public buildings and utilities using a group decision support system. J Clean Prod 2017;164:1081-92. doi:10.1016/j.jclepro.2017.07.031.

[27] Becchio C, Bottero M, Corgnati SP, Dell'Anna F. A MCDA-Based Approach for Evaluating Alternative Requalification Strategies for a Net-Zero Energy District (NZED), Springer, Cham; 2017, p. 189-211. doi:10.1007/978-3-319-39292-9_10.

[28] Todorovic B. Towards zero energy buildings: New and retrofitted existing buildings. EXPRES 2011 - 3rd IEEE Int Symp Exploit Renew Energy Sources, Proc 2011;July:7-14. doi:10.1109/EXPRES.2011.5741791.

[29] Deng S, Wang RZ, Dai YJ. How to evaluate performance of net zero energy building e A literature research. Energy 2014;71:1-16. doi:10.1016/j.energy.2014.05.007. 
[30] Centre K. Energy research challenges for Smart Cities. n.d.

[31] Dassori E, Morbiducci R. Progetti pilota di riqualificazione a energia quasi zero per quartieri e città “ intelligenti ." 2013.

[32] Ferrante A. Energy retrofit to nearly zero and socio-oriented urban environments in the Mediterranean climate. Sustain Cities Soc 2014;13:237-53. doi:10.1016/j.scs.2014.02.001.

[33] Salom J, Marszal AJ, Widén J, Candanedo J, Lindberg KB. Analysis of load match and grid interaction indicators in net zero energy buildings with simulated and monitored data. Appl Energy 2014;136:119-31. doi:10.1016/j.apenergy.2014.09.018.

[34] Kilkiş Ş. Energy system analysis of a pilot net-zero exergy district. Energy Convers Manag J 2014;87:1077-92. doi:10.1016/j.enconman.2014.05.014.

[35] Kilkiş Ş. Exergy transition planning for net-zero districts. Energy 2015;92:515-31. doi:10.1016/j.energy.2015.02.009.

[36] Rae C, Bradley F. Energy autonomy in sustainable communities - A review of key issues. Renew Sustain Energy Rev 2012;16:6497-506. doi:10.1016/j.rser.2012.08.002.

[37] Lopes RA, Martins J, Aelenei D, Lima CP. A cooperative net zero energy community to improve load matching. Renew Energy 2016;93:1-13. doi:10.1016/J.RENENE.2016.02.044.

[38] Bağci B. Towards a Zero Energy Island. Renew Energy 2009;34:784-9. doi:10.1016/j.renene.2008.04.027.

[39] Praene JP, David M, Sinama F, Morau D, Marc O. Renewable energy : Progressing towards a net zero energy island, the case of Reunion Island. Renew Sustain Energy Rev 2012;16:42642. doi:10.1016/j.rser.2011.08.007.

[40] Thomas D, Deblecker O, loakimidis CS. Optimal design and techno-economic analysis of an autonomous small isolated microgrid aiming at high RES penetration. Energy 2016;116:36479. doi:10.1016/j.energy.2016.09.119.

[41] Mendoza-Vizcaino J, Sumper A, Sudria-Andreu A, Ramirez JM. Renewable technologies for generation systems in islands and their application to Cozumel Island, Mexico. Renew Sustain Energy Rev 2016;64:348-61. doi:10.1016/j.rser.2016.06.014.

[42] Kennedy S, Sgouridis S. Rigorous classification and carbon accounting principles for low and Zero Carbon Cities. Energy Policy 2011;39:5259-68. doi:10.1016/j.enpol.2011.05.038.

[43] Kansara T, Ridley I. Post occupancy evaluation of buildings in a zero carbon city. Sustain. Cities Soc., vol. 5, 2012, p. 23-5. doi:10.1016/j.scs.2012.05.010.

[44] Koutra S, Becue V, Gallas MA, loakimidis CS. Towards the development of a net-zero energy district evaluation approach: A review of sustainable approaches and assessment tools. Sustain Cities Soc 2018;39:784-800. doi:10.1016/j.scs.2018.03.011.

[45] Todorović MS. BPS, energy efficiency and renewable energy sources for buildings greening and zero energy cities planning: Harmony and ethics of sustainability. Energy Build 2012;48:180-9. doi:10.1016/j.enbuild.2012.01.027.

[46] Eicker U, Monien D, Duminil É, Nouvel R. Energy performance assessment in urban planning competitions. Appl Energy 2015;155:323-33. doi:10.1016/j.apenergy.2015.05.094.

[47] Kerschberger A, Boehm E. From U.S. Army installation to zero energy community: The B\&O Bad Aibling Park looks to the future. ASHRAE Trans 2014;120:200-7.

[48] IEA. Distributed Generation in Liberalised Electricity Markets. Int Symp Distrib Gener Power Syst Mark Asp 2002:1G-12. doi:10.1787/9789264175976-en.

[49] Ackermann T, Andersson G, Söder L. Distributed generation: A definition. Electr Power Syst Res 2001;57:195-204. doi:10.1016/S0378-7796(01)00101-8.

[50] Bremdal BA, Olivella P. Local Electricity retail Markets for Prosumer smart grid power services. 2015.

[51] Luthander R, Widén J, Nilsson D, Palm J. Photovoltaic self-consumption in buildings: A review. 
Appl Energy 2015;142:80-94. doi:10.1016/j.apenergy.2014.12.028.

[52] Moshövel J, Kairies KP, Magnor D, Leuthold M, Bost M, Gährs S, Szczechowicz E, Cramer M, Sauer DU. Analysis of the maximal possible grid relief from PV-peak-power impacts by using storage systems for increased self-consumption. Appl Energy 2015;137:567-75. doi:10.1016/j.apenergy.2014.07.021.

[53] Linssen J, Stenzel P, Fleer J. Techno-economic analysis of photovoltaic battery systems and the influence of different consumer load profiles. Appl Energy 2017;185:2019-25. doi:10.1016/j.apenergy.2015.11.088.

[54] Klingler AL. Self-consumption with PV + Battery systems: A market diffusion model considering individual consumer behaviour and preferences. Appl Energy 2017;205:1560-70. doi:10.1016/j.apenergy.2017.08.159.

[55] Quoilin S, Kavvadias K, Mercier A, Pappone I, Zucker A. Quantifying self-consumption linked to solar home battery systems: Statistical analysis and economic assessment. Appl Energy 2016;182:58-67. doi:10.1016/j.apenergy.2016.08.077.

[56] Gaiser K, Stroeve P. The impact of scheduling appliances and rate structure on bill savings for net-zero energy communities: Application to West Village. Appl Energy 2014;113:1586-95. doi:10.1016/j.apenergy.2013.08.075.

[57] Zhou Y, Wu J, Long C, Cheng M, Zhang C. Performance Evaluation of Peer-to-Peer Energy Sharing Models. Energy Procedia 2017;143:817-22. doi:10.1016/j.egypro.2017.12.768.

[58] Zhang C, Wu J, Zhou Y, Cheng M, Long C. Peer-to-Peer energy trading in a Microgrid. Appl Energy 2018;220:1-12. doi:10.1016/J.APENERGY.2018.03.010.

[59] Sola A, Igualada L, Corchero C. Optimal Energy Management System applied to commercial self-consumption solutions. vol. 646456, 2018, p. 1-6.

[60] Agència d'Energía de Barcelona A de B. Estudi de potencial de Desenvolupament d'Energies Renovables I Eficiència Energètica a Barcelona. Barcelona: 2011.

[61] Barcelona Energia A de B. Agència d'Energía de Barcelona 2017. http://energia.barcelona/es/ (accessed March 21, 2018).

[62] Agency BE. Barcelona Energy Self-sufficiency plan. Barcelona: 2013.

[63] Barcelona Energia A de B. Balanç de l'energia 2014. 2014.

[64] Barcelona Energia A de B. ¿Cuánta energía puedes generar? 2016. http://energia.barcelona/es/cuanta-energia-puedes-generar (accessed March 20, 2018).

[65] Barcelona Energia A de B. Mapa de recursos d' energia renovable de Barcelona. 2016.

[66] Generalitat de Catalunya IC d'Energia (ICAEN). Rehabilitació energètica d'edificis (Col-lecció Quadern pràctic; 10). Barcelona: 2016.

[67] Departament d'Estadísitca de la ciutat de Barcelona A de B. Anuario Estadístico de la Ciudad de Barcelona 2017 2017. http://www.bcn.cat/estadistica/castella/dades/anuari/index.htm (accessed March 21, 2018).

[68] IDAE. Informe De Precios Energéticos Regulados. Enero 2016:7.

[69] REE. ESIOS 2017. https://www.esios.ree.es/en (accessed July 17, 2018).

[70] IDAE M de IE y T. Informe de precios regulados España. vol. 1. 2016. doi:10.1017/СВO9781107415324.004.

[71] Seto B, GI DN V, Leahy J, GI DN V, Herrschaft B, GI DN V, Butterworth B, GI DN V, Punjabi S, GI DN V. Zero Net Energy Communities : Three Cities Leading the Way 2016:1-12.

[72] Bradford A, Fanshaw B. Shining Cities 2018. 2018.

[73] Club TS. Transitioning All Electricity In U . S . Cities To $100 \%$ Renewable Energy Will Reduce Carbon Pollution, Help U . S . Meet Paris Climate Agreement Targets United States meeting the goals of the Paris Agreement . The Sierra Club. 2016.

[74] Bringault A, Eisermann M, Lacassagne S. Cities heading towards $100 \%$ renewable energy: by 
controlling their consumption 2016:28. doi:978-2-919083-09-1.

[75] Grichting A. Edges, Interfaces, and Nexus: New Paradigms for Blue Urban Landscapes in the Gulf. Int J Middle East Stud 2018;50:580-5. doi:10.1017/S0020743818000582.

[76] Farzaneh H. Devising a Clean Energy Strategy for Asian Cities. Singapore: Springer Singapore; 2019. doi:10.1007/978-981-13-0782-9. 